\title{
Paeoniflorin exerts neuroprotective effects against glutamate-induced PC12 cellular cytotoxicity by inhibiting apoptosis
}

\author{
AHONG CHEN*, HONGYUN WANG ${ }^{*}$, YUQIN ZHANG, XIAOYING WANG, \\ LISHUANG YU, WEN XU, WEI XU and YU LIN \\ College of Pharmacy of Fujian University of Traditional Chinese Medicine, Fuzhou, Fujian 350122, P.R. China
}

Received October 17, 2016; Accepted July 3, 2017

DOI: $10.3892 /$ ijmm.2017.3076

\begin{abstract}
Paeoniflorin (PF) is an active ingredient of Radix Paeoniae, which is known to exert neuroprotective effects. However, the mechanims behind the neuroprotective effects of $\mathrm{PF}$ are not yet fully understood. The apoptosis of neurons plays an important role in the cerebral ischemia-induced cascade response. This study aimed to investigate neuroprotective effects of PF against glutamate-induced PC12 cellular cytotoxicity and to determine whether these effects are mediated via the inhibition of apoptosis in vitro and the activity of mitochondrial apoptosis-associated proteins in PC12 cells. Exposure of the PC12 cells to glutamate induced cell morphological changes, significantly decreased cell viability and induced apoptosis, with similar results being observed from the Hoechst 33342 staining and Annexin V/PI staining experiments. Glutamate also increased the lactate dehydrogenase release by the PC12 cells. However, treatment with PF prevented these effects. Furthermore, PF inhibited Bax and Bad expression and increased Bcl-2 and Bcl-xL expression; it also decreased the levels of downstream protein (caspase-3 and caspase-9). Collectively, our results indicate that $\mathrm{PF}$ protects $\mathrm{PC} 12$ cells against glutamateinduced neurotoxicity possibly through the inhibition of the expression of mitochondrial apoptosis-associated proteins.
\end{abstract}

\section{Introduction}

Stroke is the third cause of mortality worldwide and is clinically characterized by a clear three-high (high incidence, high morbidity and high mortality) phenomenon $(1,2)$. Ischemic stroke, which affects approximately $80 \%$ patients with stroke, is

Correspondence to: Professor Wei Xu or Professor Yu Lin, College of Pharmacy of Fujian University of Traditional Chinese Medicine, 1 Qiuyang Road, Minhou Shangjie, Fuzhou, Fujian 350122, P.R. China E-mail: xwfjlab@163.com

E-mail: lyfjlab@163.com

${ }^{*}$ Contributed equally

Key words: paeoniflorin, neuroprotective, glutamate, PC12, apoptosis currently a mainly leading cause of disability and mortality in the aged population, due to limited medication and therapy (3). Nowadays, the only FDA-approved treatment for ischemic stroke is plasminogen activator, which is administered within $4.5 \mathrm{~h}$ of stroke onset (4). Therefore, novel therapeutic strategies are urgently required.

Recently, several hypotheses have been put forward to explain the pathophysiological processes of stroke. Increasing evidence indicates that neuronal cell death is a main cellular event in the pathogenesis of ischemic brain injury, which is often in the form of apoptosis (5). Apoptosis is characterized by cell shrinkage, chromatin condensation, and the formation of cytoplasmic blebs and apoptotic bodies, which lead to changes in cell permeability and cell membrance damage (6). 3-(4,5-Dimethylthiazol-2-yl)2,5-diphenyltetrazolium bromide (MTT) assay, as well as lactate dehydrogenase (LDH) assay are usually employed to evaluate cell viability. Succinate dehydrogenase in the mitochondria of living cells can revert exogenous MTT into formazan; however, it cannot do so in dead cells. LDH is a soluble cytosolic enzyme present in most eukaryotic cells and can be released into the culture medium upon cell death due to plasma membrane damage (7). Thus, MTT and LDH assays are regarded as the a valuable enzyme parameters in apoptosis.

The mitochondrial pathway is a central pathway leading to apoptosis in cerebral ischemia $(8,9)$. A number of genes and proteins can influence or instigate the progression of apoptosis along the mitochondrial pathway (10). The most important genes associated with apoptosis are proteins of the Bcl family and caspases $(11,12)$. Bcl-2/Bax family members are key regulatory factors in the mitochondrial apoptotic pathway $(13,14)$. They are divided into two groups, anti-apoptotic (Bcl-2, Bcl-xL) and pro-apoptotic (Bax, Bad) proteins. Upon stimulation with pro-apoptotic factors, Bax translocates from the cytoplasm to inthe mitochondrial membrane, which alters the permeability of the mitochondrial membrane and promotes the release of cytochrome $c$ (Cyt $c$ ) from the mitochondria into the cytoplasm (11). It has been proven that the activity of the Bcl-2 protein may be regulated through caspase cleavage under various circumstances. The apoptotic cascade is subsequently initiated, eventually leading to apoptosis (15).

Mitochondrial dysfunction leads to characteristic morphological changes in neurons and results in abnormal upstream and downstream protein expression in the mitochondrial pathway (16). 
In order to combat neuronal cell death, nowadays, researchers are focusing on herbal extracts or their compounds due to their novel structures and few side-effects. Paeoniflorin (PF) (Fig. 1), a monoterpene glycoside, is a natural compound and the main active ingredient of Radix Paeoniae (dried root of Paeonia lactiflora Pall.). It has been reported that $\mathrm{PF}$ exerts neuroprotective effects in in vivo models of cerebral ischemia (17-22) and in in vitro models of cell injury induced by $\mathrm{H}_{2} \mathrm{O}_{2}$ (23), 1-methyl-4-phenylpyridinium (MPP ${ }^{+}$(24), glutamate (25), $\mathrm{A} \beta_{25-35}$ (26) and lipopolysaccharide (27). The effects of PF have been attributed to the involvement of multiple modulatory pathways, such as anti-oxidative stress and anti-inflammatory. Moreover, our recent study suggested that PF exerted stable and potent neuroprotective effects against cerebral ischemic injury and protected against N-methylD-aspartate (NMDA)-induced cell apoptosis and neuronal loss (22). In a previous study of ours, we also found that PF was one of the compounds found in the brain tissue and cerebrospinal fluid of rats administerd PF after suffering cerebral ischemia injury (28). Thus, as a continuation, the aim of this study was to further investigate the neuroprotective effects of $\mathrm{PF}$ against glutamate-induced PC12 cellular cytotoxicity and to elucidate whether the mitochondrial apoptosis-associated pathway is involved in these neuroprotective effects. Furthermoe, we investigated whether the cellular permeability of $\mathrm{PF}$ is associated with its protective effects.

\section{Materials and methods}

Reagents. PF ( $>98 \%$ purity) was purchased from the National Institute for the Control of Pharmaceutical and Biological Products (Beijing, China). Dimethyl sulfoxide (DMSO), glutamate, 3-(4,5-dimethylthiazol-2-yl)-2,5-diphenyltetrazolium bromide (MTT) and Hoechst 33342 were all purchased from Sigma-Aldrich (St. Louis, MO, USA). Trypsin, RPMI-1640 medium, fetal bovine serum (FBS) and penicillin-streptomycin were all purchased from Hyclone (Logan, UT, USA). The LDH assay kit was from Nanjing Jiancheng Biochemical Reagent Co., Ltd. (Nanjing, China). The Annexin V/propidium iodide (PI) apoptosis assay kit was obtained from Roche Diagnostics (Indianapolis, IN, USA). Antibodies to caspase-3 (\#9665), caspase-9 (\#9508), Bcl-xL (\#2764), Bcl-2 (\#3498), p-21 (\#2947), p-53 (\#2524) and cleaved PARP (\#9545) were all purchased from Cell Signaling Technology, Inc. (Danvers, MA, USA). Antibodies to $\mathrm{p}$-Bad and Bax were both obtained from Sangon Biological Engineering Co., Ltd. (Shanghai, China). The secondary antibodies were from Xiamen Lulong Biotech Development Co., Ltd. (Xiamen, China). Polyvinylidene fluoride membranes were from Merck KGaA (Darmstadt, Germany). All other reagents were from the Beyotime Institute of Biotechnology (Nanjing, China) unless otherwise stated.

Cell culture and treatment. PC12 cells (North Carolina Chuanglian Biotechnology Research Institute, Beijing, China) were maintained in RPMI-1640 medium supplemented with $10 \%$ FBS and $1 \%$ penicillin-streptomycin mixed solution at $37^{\circ} \mathrm{C}$ in a $5 \% \mathrm{CO}_{2}$ incubator. After seeding onto 96-, 24- or 6 -well plates for $24 \mathrm{~h}$, the cells were cultured in medium without serum and incubated in the presence or absence of

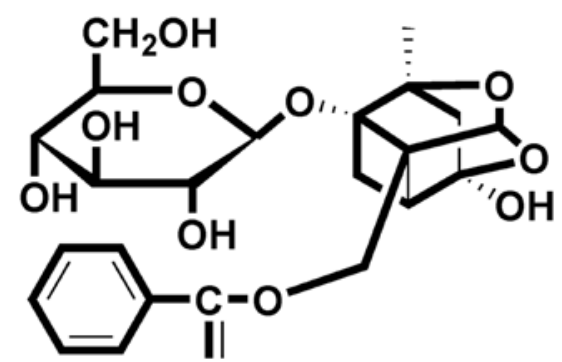

Figure 1. Chemical structure of paeoniflorin (PF).

various concentrations of PF for $24 \mathrm{~h}$ followed by exposure to glutamate for $24 \mathrm{~h}$. The control cells were not treated with PF or glutamate as the vehicle control. The glutamate-exposed cells were treated with glutamate for $24 \mathrm{~h}$ alone.

Determination of cell viability. Cell viability was measured by MTT assay, as well as by LDH assay. Briefly, for the MTT assay, following treatment, $10 \mu \mathrm{l}$ MTT solution $(5 \mathrm{mg} / \mathrm{ml})$ were added to each well for an additional $4 \mathrm{~h}$ of incubation. The MTT reagent was then replaced with DMSO (100 $\mu \mathrm{l} /$ well) carefully to dissolve the formazan crystals. The absorbance at $570 \mathrm{~nm}$ was measured using a microplate reader (Infinite M200 Pro; Tecan, Männedorf, Switzerland). For the LDH assay, following treatment, the culture medium of each well was collected for LDH determination. The optical absorbance at $450 \mathrm{~nm}$ was measured using a microplate reader. Results were expressed as the percentage of the absorbance of the control cells, which was considered as $100 \%$.

Analysis of morphological changes. The PC12 cells were cultured and treated in a similar manner as described above. Following treatment, morphological changes were observed under a phase-contrast microscope (TS-100F; Nikon, Tokyo, Japan) and images of the cells were acquired using a digital camera(Olympus, Tokyo, Japan).

Cell apoptosis. Cell apoptosis was determined using two different methods, as follows:

i) Fluorescence staining. Following treatment as described above, the PC12 cells were stained with Hoechst $33342(5 \mu \mathrm{g} /$ $\mathrm{ml}$ ) after removing the culture medium, and the PC12 cells were then observed under a fluorescence microscope (Advanced Microscopy Group, Bothell, WA, USA) at x200 magnification in order to observe the apoptotic cells.

ii) Flow cytometric analysis. Following treatment, the PC12 cells were collected and quantified according to the manufacturer's instructions. Briefly, the PC12 cells were resuspended in binding buffer and stained with Annexin V/ PI for $15 \mathrm{~min}$. The samples were then analyzed using a flow cytometer with an excitation wavelength of $488 \mathrm{~nm}$ and an emission wavelength of $530 \mathrm{~nm}$ (Becton-Dickinson, Bedford, MA, USA). Apoptotic cells were expressed as a percentage of the total number of cells.

Cellular permeability analysis by high-performance liquid chromatography (HPLC). In this study, we found that PF at $100 \mu \mathrm{M}$ exerted a significant neuroprotective effect; thus, we 
selected this concentration to explore its cell permeability. Briefly, the cells were treated with $100 \mu \mathrm{M}$ PF for 4,8 and $24 \mathrm{~h}$ to examine the cellular permeability of PF. Following treatment, the cells were washed with Tris-buffered saline and collected in a microcentrifuge tube with ice-cold lysis phosphate-buffered saline (PBS) buffer. The collections were vortexed after being sonicated. Intracellular PF was extracted by centrifugation at $12,000 \mathrm{x} g$ for $15 \mathrm{~min}$ at $4^{\circ} \mathrm{C}$. The supernatant was then collected and filtered through a $0.22 \mu \mathrm{m}$ PTFE membrane (Millipore, Milford, MA, USA) prior to injecting into the HPLC autosampler (Shimadzu Co., Kyoto, Japan). The samples were injected into the HPLC system (Shimadzu Co.) equipped with an diamonsil C18 reversed-phase column (I.D., $4.6 \mathrm{~mm} \times 250 \mathrm{~mm}, 5 \mu \mathrm{m})$ at a flow rate of $1.0 \mathrm{ml} / \mathrm{min}$ using $30 \%$ water (containing $0.1 \%$ methanoic acid) and $70 \%$ acetonitrile as the mobile phase with a detection wavelength of UV $230 \mathrm{~nm}$.

Western blot analysis. Following treatment, the cells were harvested and lysed using RIPA lysis buffer containing protease inhibitor cocktail (PMSF) on ice, and were subsequently centrifuged at $12,000 \mathrm{x}$ for $15 \mathrm{~min}$ at $4^{\circ} \mathrm{C}$. The supernatant was collected and the protein concentration was determined by the BCA method. The protein expression levels was then analyzed as described in a previous study (29). Briefly, protein was electrophoresed on $12 \%$ density SDS acrylamide gels, transferred from the gel to PVDF membranes using an electric transfer system, and incubated with antibodies to caspase-3 (1:500), caspase-9 (1:500), p-Bad (1:500), Bcl-xL (1:1,000), Bax (1:1,000), Bcl-2 $(1: 1,000)$, cleaved PARP $(1: 1,000)$ and $\beta$-actin $(1: 1,000)$ overnight at $4^{\circ} \mathrm{C}$. Subsequently, the membranes were incubated for $2 \mathrm{~h}$ at room temperature with a secondary antibody (1:7,000). Finally, they were evaluated using the ECL western detection reagents on Image Lab analysis software (Bio-Rad Laboratories, Inc., Hercules, CA, USA). $\beta$-actin was used as a loading control. Three repeats of the experiments were performed.

Real-time PCR analysis. Following treatment, the cells were harvested and total RNA was extracted using TRizol reagent (Invitrogen, Barcelona, Spain). mRNA was reverse transcribed into cDNA according to the manufacturer's instructions of the PrimeScript ${ }^{\circledR}$ RT reagent kit (Takara Bio, Inc., Otsu, Japan). cDNA was used as template for the Real-Time PCR assays with Power SYBR ${ }^{\circledR}$-Green PCR Master mix (Thermo Fisher Scientific, Inc., Shanghai, China). The PCR analysis was performed in a 7900 Real-Time PCR system (Applied Biosystems, Inc., Foster City, CA, USA) and the results were analyzed with software provided by the 7900 Real-Time PCR system. The results were expressed as the ratio between glutamate and control cells. Primer sequences used in the reactions were as follows: Bax reverse primer, 5'-GAT CAG CTC GGG CAC TTT AG-3' and forward primer, 5'-TGC AGA GGA TGA TTG CTG AC-3'; Bcl-2 reverse primer, 5'-ATG CCG GGT CAG GTA CTC AG-3' and forward primer, 5'-GGT GGT GGA GGA ACT CTT CA-3'.

Statistical analysis. Data are presented as the means \pm standard deviation (SD). One-way analysis of variance (ANOVA) [SPSS 20.0 statistical software (SPSS, Inc., Chicago, IL, USA)] followed by a post hoc LSD test were used to evaluate multiple group differences. A value of $\mathrm{P}<0.05$ was considered to indicate a statistically significant difference.

\section{Results}

Effect of PF on PC12 cell viability. The effect of PF itself on the basal growth of PC12 cells was examined. The results (Fig. 2A) revealed that compared with the control group, the viability of the PC12 cells treated with PF alone at various concentrations was not significantly increased or decreased (in cells treated wth PF at 100,200 and $300 \mu \mathrm{m}$, viability was $102.11 \pm 6.2$, $100.11 \pm 6.5$ and $99.81 \pm 6.6 \%$ of control, respectively).

Cytotoxic effects of glutamate on PC12 cells. The concentration-dependent response of glutamate-induced cytotoxicity was determined by MTT assay. The results revealed that cell viability was inhibited by glutamate with an $\mathrm{IC}_{50}$ value of $17.181 \mathrm{mM}$ (Fig. 2B); thus, glutamate at the concentration of $15 \mathrm{mM}$ was selected for use in the subsequent experiments.

Effect of PF on the glutamate-induced decrease in PC12 cell viability. As shown in Fig. $2 \mathrm{C}$, cell viability decreased to $51.5 \%$ of control following exposure to $(15 \mathrm{mM})$ for $24 \mathrm{~h}$. However, cell viability markedly increased to $59.4,67.4$ and $75.4 \%$ of the control following treatment with various concentrations of $\mathrm{PF}(100,200$ and $300 \mu \mathrm{M})$ prior to exposure to. glutamate

Effect of PF on $L D H$ release. The effect of PF on the release of $\mathrm{LDH}$ in the glutamate-exposed PC12 cells is shown in Fig. 2D. Exposure to glutamate $(15 \mathrm{mM})$ for $24 \mathrm{~h}$ resulted in an increase in $\mathrm{LDH}$ release into the medium, which was significantly increased (261.92\%) as compared with the control group. However, pre-treatment with various concentrations of PF (100, 200 and $300 \mu \mathrm{M}$ ) for $24 \mathrm{~h}$ decreased $\mathrm{LDH}$ leakage to 213.58, 150.51 and $122.02 \%$, respectively.

Effect of PF on the apoptosis of PC12 cells. As shown in Fig. 3A, compared with the control group, the morphology of the PC12 cells in the glutamate group was markedly altered; the cells shrank and became round. However, cell morphology was protected when the cells were pre-treated with various concentrations of PF prior to exposure to glutamate.

Fluorescence staining was employed to investigate the nuclear of apoptosis cell. As shown in the Fig. 3B, apoptotic cells became thinner with pyknotic nuclei and exhibited light blue fluorescence following exposure to glutamate for $24 \mathrm{~h}$; in addition, more nuclear fragmentation was observed than in the control cells. However, pre-treatment with various concentrations of PF (100, 200 and $300 \mu \mathrm{M})$ attenuated these changes and reduced the number of apoptotic cells.

To quantitatively demonstrate the effect of PF on glutamate-induced apoptosis, Annexin V/PI staining was evaluated by flow cytometric analysis. As shown in Fig. 4, 3.54\% of the total cells were apoptotic in the control group. However, the apoptotic rate was markedly increased to $9.86 \%$ vs. the control group following incubation with glutamate. Treatment with PF $(100,200$ and $300 \mu \mathrm{M})$ markedly reduced the apoptotic ratio of the cells (cell apoptotic rate was 8.48, 6.03 and 5.9\%, respectively). 

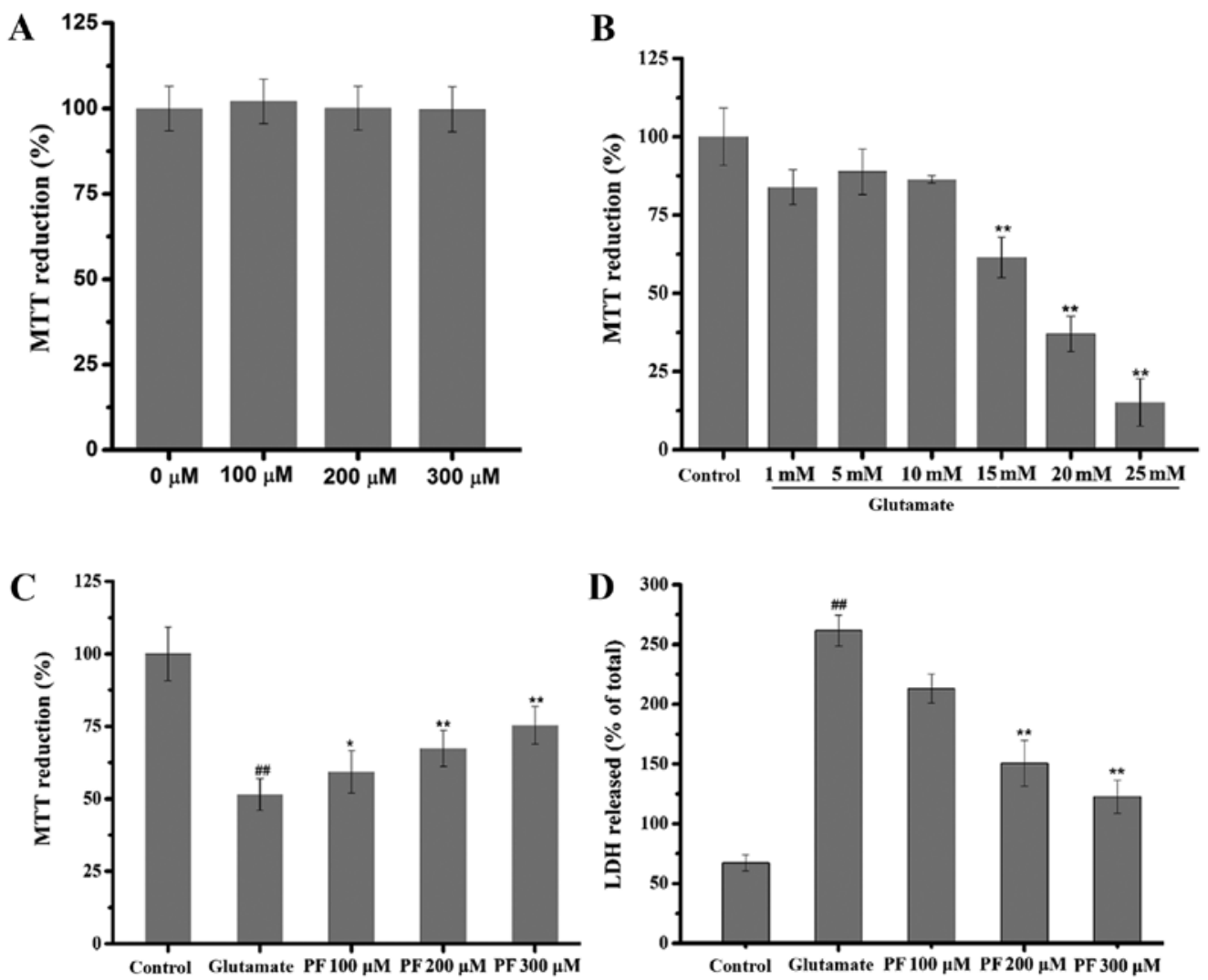

Figure 2. Effect of paeoniflorin (PF) and glutamate on PC12 cells. (A) Effect of PF itself on basal growth of PC12 cells. PC12 cells were treated with various concentrations of $\mathrm{PF}(100,200$ and $300 \mu \mathrm{M})$ for $24 \mathrm{~h}$, and cell viability was then assessed by MTT assay. Data are represented as the means $\pm \mathrm{SD}, \mathrm{n}=6$ wells for each group. (B) Effect of glutamate on the viability of PC12 cells. PC12 cells were exposed to various concentrations of glutamate $(1,5,10,15,20$ and $25 \mathrm{mM})$ for $24 \mathrm{~h}$, and cell viability was then assessed by MTT assay. Data are represented as the means \pm SD, n=6 wells for each group. ${ }^{* *}<<0.01$ vs. control group. (C) Effect of $\mathrm{PF}$ on cell viability in glutamate-exposed cells and (D) on lactate dehydrogenase (LDH) leakage. Following treatment of the cells with various concentrations of PF (100, 200 and $300 \mu \mathrm{M})$ for $24 \mathrm{~h}$ and exposure to $15 \mathrm{mM}$ of glutamate for $24 \mathrm{~h}$, cell viability was assessed by (C) MTT assay and (D) LDH assay was determined using a microplate reader at 570 and $450 \mathrm{~nm}$, respectively. Data are represented as the means \pm SD, $n=6$ wells for each group. ${ }^{\# \#}<<0.01 \mathrm{vs.} \mathrm{control}$ group; ${ }^{*} \mathrm{p}<0.05,{ }^{* *} \mathrm{p}<0.01$ vs. glutamate group. All data were analyzed by one-way analysis of variance (ANOVA) (SPSS 20.0 statistical software) followed by a post hoc LSD test to evaluate multiple group differences.

Effects of PF on the expression of apoptosis-related proteins in PC12 cells. The Bcl-2, Bax, Bcl-xL and p-Bad proteins belong to the Bcl-2 family and play an important role in cell apoptosis. Thus, we examined the expression of these proteins. The results (Fig. 5) revealed that compared with the control group, the protein expression levels of Bax and p-Bad were significantly increased following exposure to $15 \mathrm{mM}$ glutamate for $24 \mathrm{~h}$, whereas the levels of Bcl-2 and Bcl-xL were significantly decreased. However, after the cells were incubated with various concentrations of $\mathrm{PF}(100,200$ and $300 \mu \mathrm{M})$ for $24 \mathrm{~h}$ prior to expose to glutamate, the protein expression levels of Bax and p-Bad were decreased to 1.7- and 0.9-fold, 1.3- and 1.2-fold, and 1.1- and 1.1-fold of the glutamate group value, respectively, and the levels of Bcl-2 and Bcl-xL increased to 1.2- and 0.4-fold, 1.0- and 0.9-fold, 1.1- and 0.9-fold of the glutamate group value.

The Bcl-2 family exerts its pro- or anti-apoptotic effects and activates caspase-9 and caspase-3, leading to apoptosis. Thus, we also examined the levels of caspase- 9 and caspase- 3 . As shown in Fig. 6, glutamate elevated the activity of caspase-3 and caspase-9 in the PC12 cells, while the levels of caspase-3 and caspase- 9 were significantly decreased by PF. Moreover, PARP is a family of proteins involved in a number of cellular processes involving mainly DNA repair and programmed cell death. It can be activated in cells experiencing stress and/or
DNA damage and is inactivated by caspase cleavage. We also thus exmained the expression of PARP. As shown in Fig. 6, exposure to glutamate for $24 \mathrm{~h}$ significantly increased the protein level of cleaved PARP, whereas this was markedly reversed by PF pre-treatment.

Effects of PF on the mRNA expression of Bcl-2 and Bax. As presented in Fig. 7, the real-time PCR analysis revealed that exposure to glutamate increased the mRNA level of Bax and decreased the mRNA level of Bcl-2. By contrast, PF treatment profoundly downregulated the mRNA level of Bax and upregulated the mRNA level of Bcl-2.

Effect of PF on cell permeability. The permeability of PF across the membrane barrier in PC12 cells was evaluated by HPLC with the index of the intracellular content of PF. As shown in Fig. 8, treatment with $100 \mu \mathrm{M}$ PF for 8, 12 and $24 \mathrm{~h}$ resulted in an increase of PF incorporation to $0.54,13.4$ and $24 \mu \mathrm{M}$, respectively.

\section{Discussion}

Ischemic stroke is third leading cause of mortality worldwide and is associated with a high incidence of long-term disability 
A
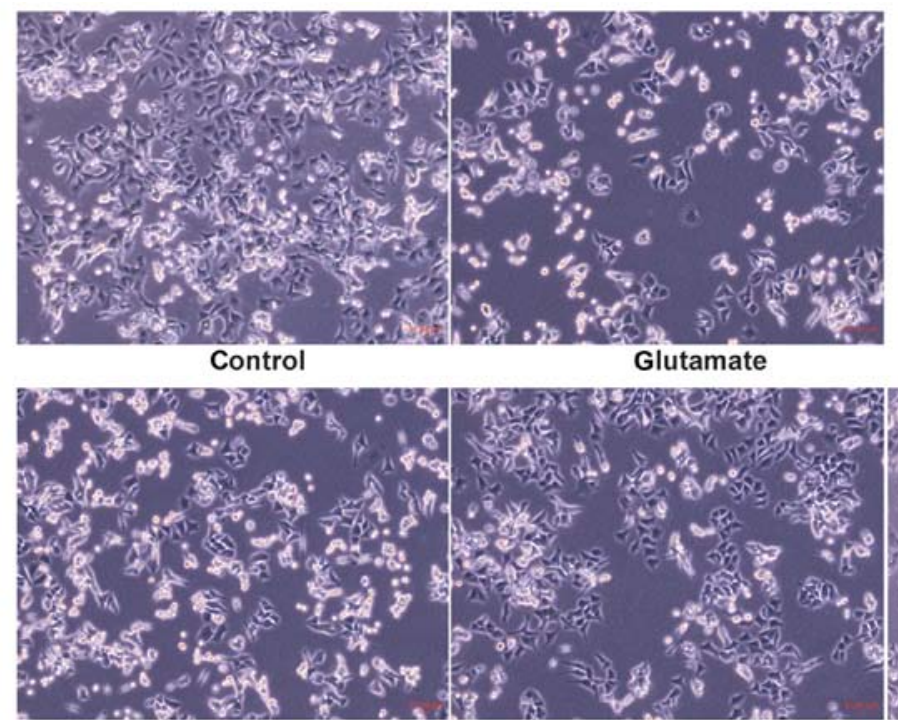

PF $100 \mu \mathrm{M}$

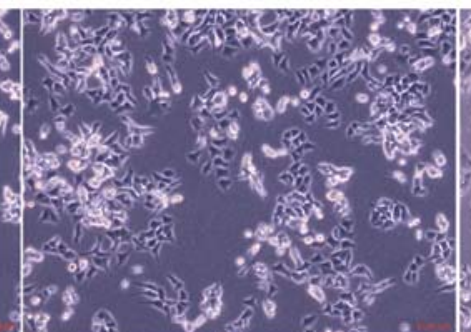

PF $200 \mu \mathrm{M}$

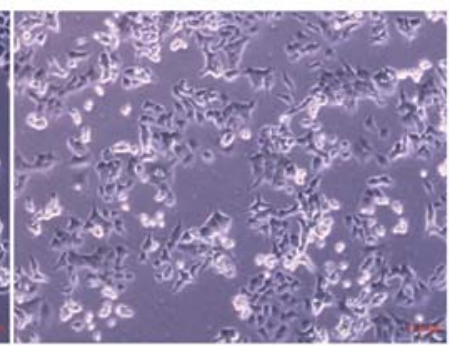

PF $300 \mu \mathrm{M}$

B

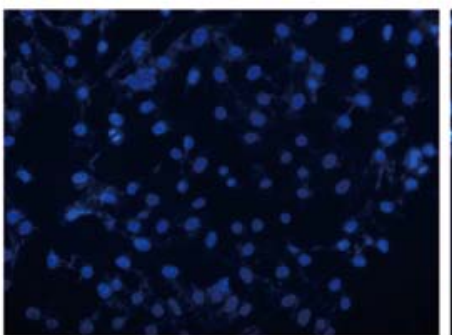

Control

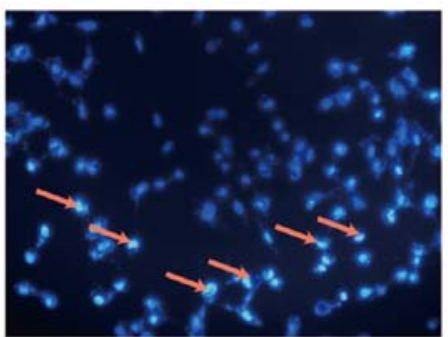

Glutamate

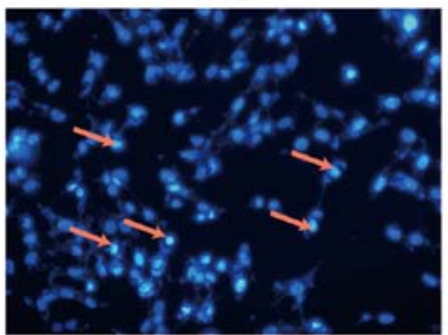

PF $100 \mu M$

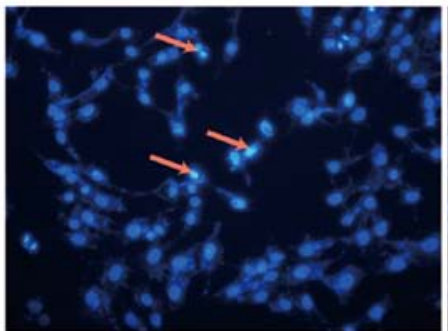

PF $200 \mu \mathrm{M}$

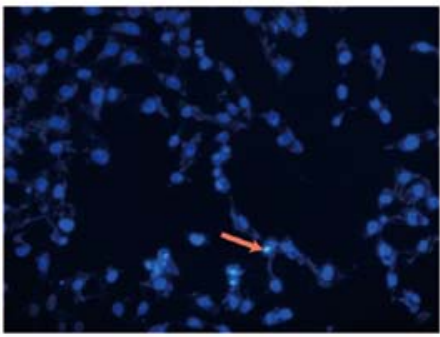

PF $300 \mu \mathrm{M}$

Figure 3. Effects of paeoniflorin (PF) in glutamate-induced (A) cell morphological changes and (B) cell apoptosis. Following treatment of the cells with various concentrations of PF (100, 200 and $300 \mu \mathrm{M})$ for $24 \mathrm{~h}$ and $15 \mathrm{mM}$ of glutamate for $24 \mathrm{~h}$, fluorescence staining was employed to investigate the nuclear apoptosis of cells; arrows represent apoptotic cells.

in surviving individuals (30). It triggers a complex cascade of pathophysiological processes, including excitotoxicity, oxidative stress, calcium overload, inflammation and apoptosis $(31,32)$. Excitotoxicity is a major event that induces neuronal death in ischemic stroke (33). Glutamate is an excitatory neurotransmitter, which exists in abundance in the hippocampus, the brain cortex and other body parts of the central nervous system. Under pathological conditions, the content of glutamate is increased, and causes the influx of $\mathrm{Ca}^{2+}$, leading to the apoptosis and necrosis of neurons through various mechanisms. As such, glutamate is widely used as an excitotoxicity-inducing agent to study the molecular mechanisms and to develop drugs for ischemic stroke therapy (34-36).

The exogenous addition of glutamate into cultured cells induces cells to undergo a series of processes, such as cell excitotoxicity, DNA fragmentation and cell apoptosis. PC12 cells are derived from Rattus norvegicus pheochromocytoma tumors, and it has been proven that their cell morphology and physiological function are very similr to those of neurons, and the NMDA receptor with strong affinity for glutamate, is expressed in abundance in PC12 cell membranes $(37,38)$. Therefore, the PC12 cell line has been used as an in vitro experimental model of cerebral ischemia. Previous studies in PC12 cells have found that glutamate exposure significantly induces apparent cell morphological changes, a decrease in cell viability and apoptosis $(39,40)$. In this study, the exposure of the PC12 cells to glutamate significantly altered the cell morphological characteristics and decreased cell viability; similar results were obtained from Hoechst 33342 staining and Annexin V/PI staining. Glutatamate also increased the LDH release from PC12 cells. These findings were consistent with those of previous studies $(39,40)$. Of note, pre-treatment of the PC12 cells with PF markedly increased cell viability and decreased the LDH release, which implied that PF protected 

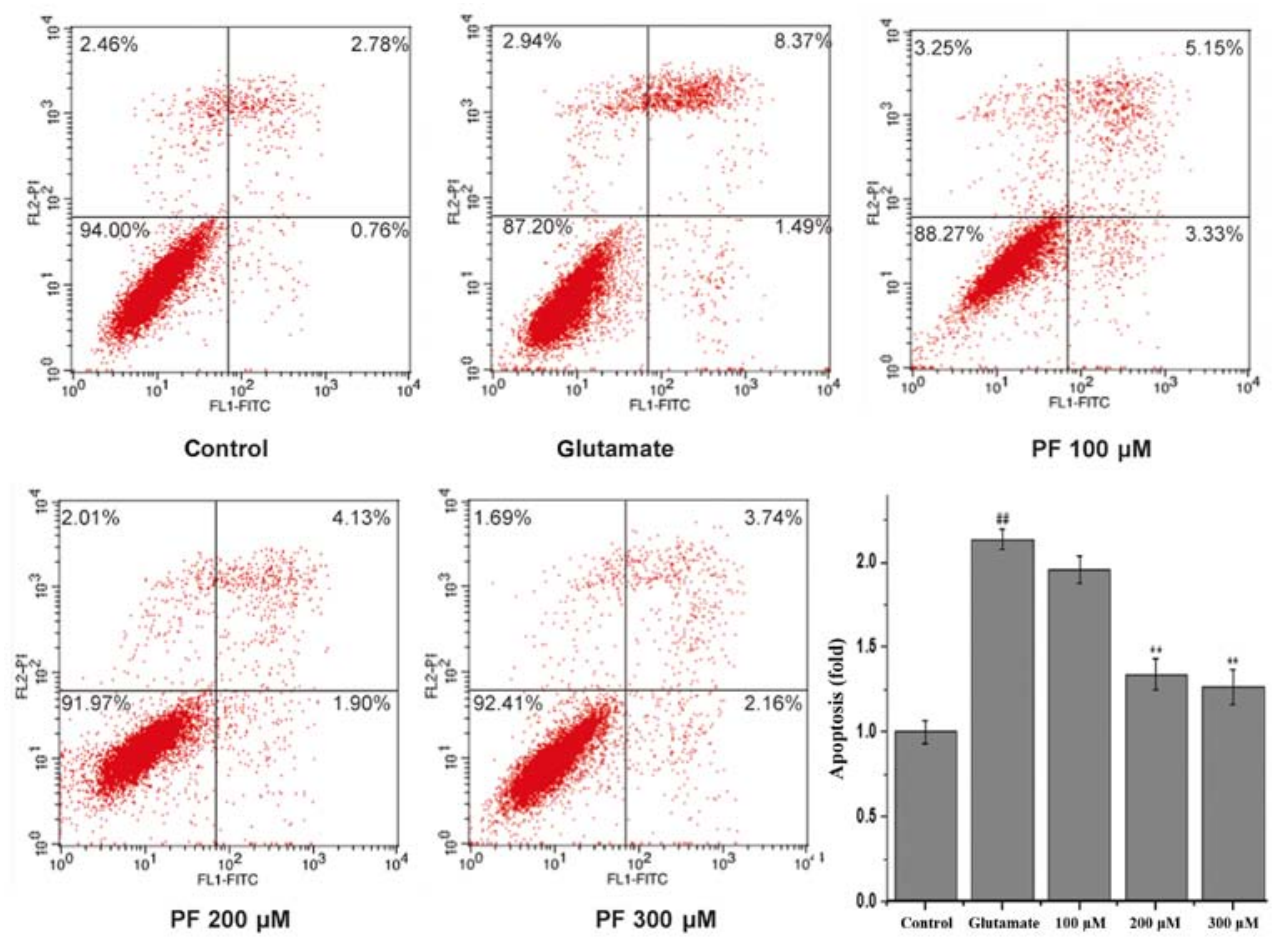

Figure 4. Effect of paeoniflorin (PF) on glutamate-induced PC12 cell apoptosis by Annexin V/PI staining (flow cytometric analysis). PC12 cells were pre-treated with various concentrations of PF $(100,200$ and $300 \mu \mathrm{M})$ for $24 \mathrm{~h}$ and then exposed to $15 \mathrm{mM}$ of glutamate for $24 \mathrm{~h}$. Cell apoptosis was examined by flow cytometric analysis. Results were obtained from 3 independent experiments.
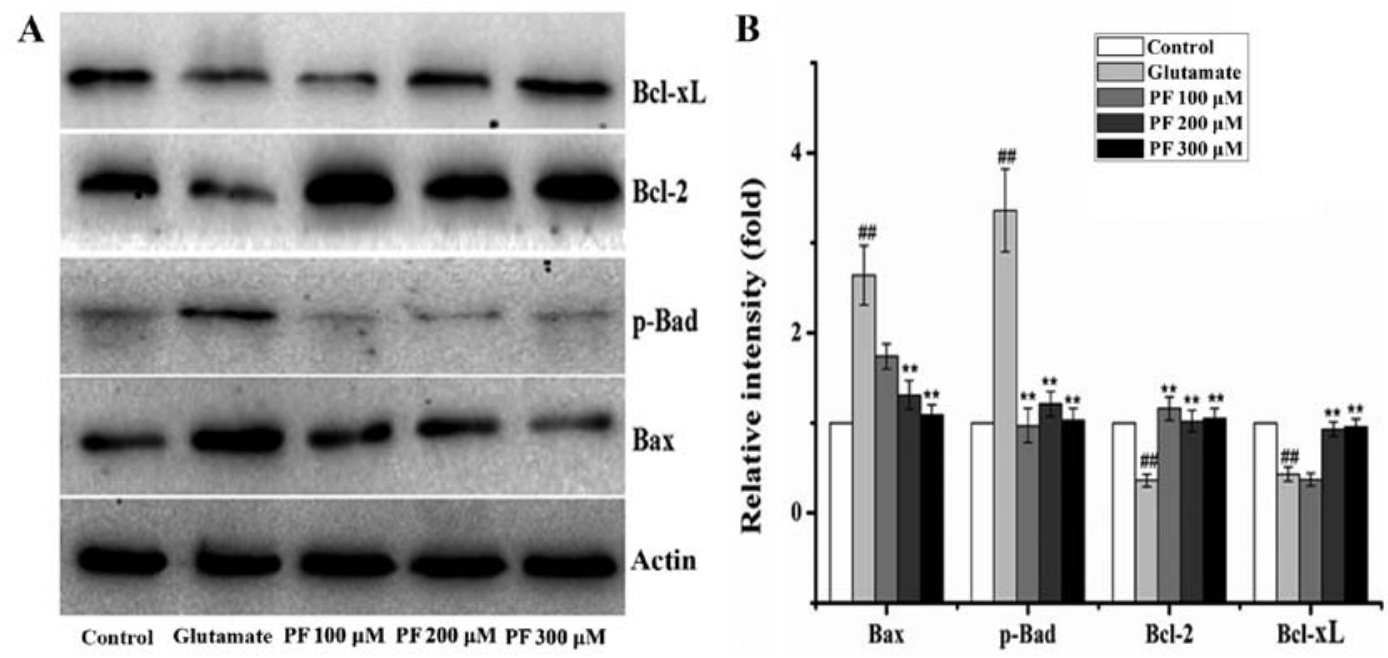

Figure 5. Effect of paeoniflorin (PF) on protein levels in PC12 cells. (A) The level of Bcl-xL, Bcl-2, p-Bad and Bax was determined by western blot analysis. PC12 cells were pre-treated with various concentrations of $\mathrm{PF}(100,200$ and $300 \mu \mathrm{M})$ for $24 \mathrm{~h}$ and exposed to $15 \mathrm{mM}$ of glutamate for $24 \mathrm{~h}$. $\beta$-actin was used as the internal control. (B) The relative optical densities were indicated. Values given are the means \pm SD ( $n=3$ ). One-way analysis of variance (ANOVA) (SPSS 20.0 statistical software) followed by a post hoc LSD test to evaluate multiple group differences. ${ }^{\# \#} \mathrm{p}<0.01$ vs. control group; ${ }^{* *} \mathrm{p}<0.01$ vs. glutamate group.

the PC12 cells agaist glutamate-induced cytotoxicity, at least partially, due to its anti-apoptotic effects.

To the best of our knowledge, the apoptosis of neurons plays an important role in the cerebral ischemia inducedcascade response $(41,42)$. A number of genes and proteins can influence the progression of apoptosis along the mitochondrial pathway (10). The most important genes of apoptosis are proteins of the Bcl family and caspases $(11,12)$. There are two groups, anti-apoptotic (Bcl-2, Bcl-xL) and pro-apoptotic (Bax, $\mathrm{Bad}$ ) proteins in the Bcl-2 family (42). The abnormal expression levels of pro-apoptotic proteins and anti-apoptotic proteins are considered to determine cell death or survival by controlling apoptosis $(43,44)$. Previous studies have indicated that the Bcl-2 family plays a vital regulatory role in cell apoptosis $(15,45)$. The $\mathrm{Bcl}-2$ and $\mathrm{Bcl}-\mathrm{xL}$ proteins are the major anti-apoptotic factors. In the present study, treatment with PF prior to exposure to glutamate for $24 \mathrm{~h}$ significantly increased the Bcl-2 and Bcl-xL expression level and decreased the Bax and Bad expression level. Moreover, Bcl-2 mRNA expression was increased and Bax mRNA expression was decreased. This result implied that 

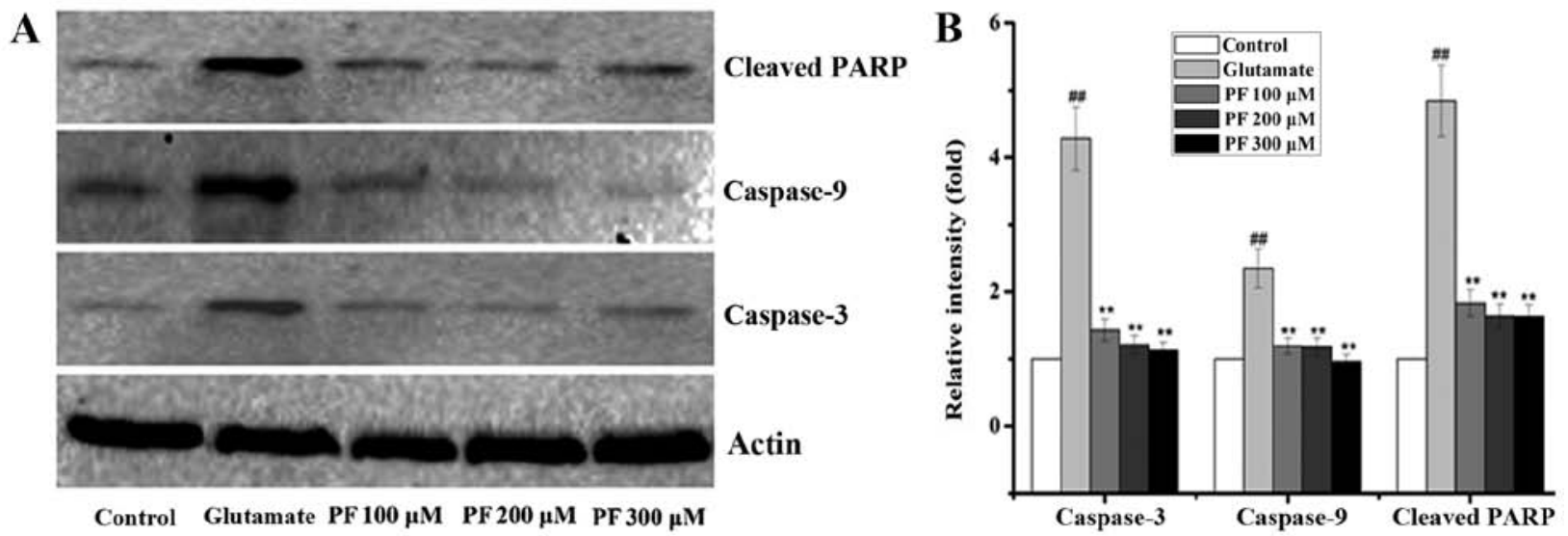

Figure 6. Effect of paeoniflorin (PF) on protein levels in PC12 cells. (A) The level of cleaved PARP, caspase-3 and caspase-9 was determined by western blot analysis. PC12 cells were pre-treated with various concentrations of PF (100,200 and $300 \mu \mathrm{M})$ for $24 \mathrm{~h}$ and exposed to $15 \mathrm{mM}$ of glutamate for $24 \mathrm{~h}$. $\beta$-actin was used as the internal control. (B) The relative optical densities were indicated. Values given are the means $\pm \mathrm{SD}(\mathrm{n}=3)$. And one-way analysis of variance (ANOVA) (SPSS 20.0 statistical software) followed by a post hoc LSD test to evaluate multiple group differences. ${ }^{\# \#} \mathrm{p}<0.01$ vs. control group; ${ }^{* *} \mathrm{p}<0.01 \mathrm{vs.} \mathrm{glutamate}$ group.

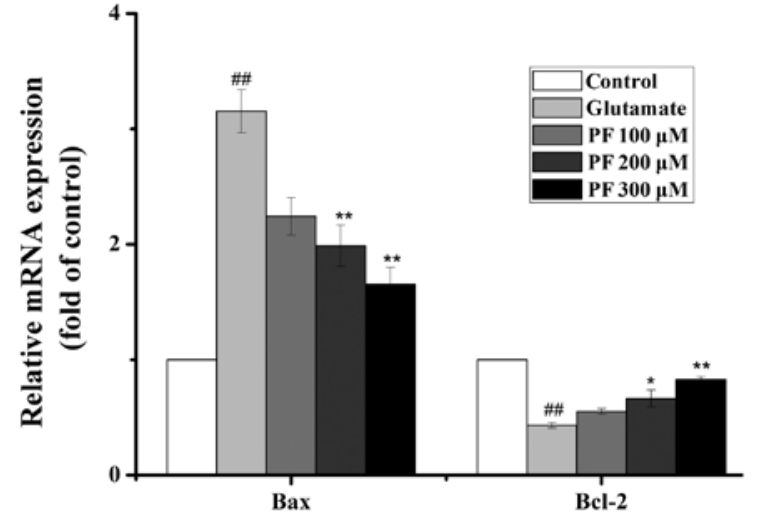

Figure 7. Effect of paeoniflorin (PF) on mRNA levels in PC12 cells. The level of Bax and Bcl-2 was determined by real-time PCR. PC12 cells were pre-treated with various concentrations of $\mathrm{PF}(100,200$ and $300 \mu \mathrm{M})$ for $24 \mathrm{~h}$ and exposed to $15 \mathrm{mM}$ of glutamate for $24 \mathrm{~h}$. GAPDH was used as the internal control. And one-way analysis of variance (ANOVA) (SPSS 20.0 statistical software) followed by a post hoc LSD test to evaluate multiple group differences. ${ }^{\# \#} \mathrm{p}<0.01$ vs. control group; ${ }^{*} \mathrm{p}<0.05,{ }^{* *} \mathrm{p}<0.01$ vs. glutamate group.

the neuroprotective effects of PF are likely connected with the inhibition of Bax and Bad expression and the increase of Bcl-2 and Bcl-xL expression.

Apoptogenic factors release and activate the executioners of apoptosis, the caspases (46). It has been found that caspases play an important role in the apoptotic process; the regulation of caspases has a shown promising effect in attenuating apoptosis (47). Caspase-3 is the executive factor of apoptosis, as it activates DNA fragmentation, which in turn activates endonucleases to cleave nuclear DNA and as a result, leads to cell death $(48,49)$. Caspase- 9 is an initiator caspase and is activated during programmed cell death (apoptosis). Once initiated, caspase- 9 then cleaves pro-caspase- 3 , which cleaves several cellular targets. In the present study, glutamate markedly increased caspase- 3 and caspase- 9 protein expression. However, pre-incubation with PF decreased their expression. Combined with results of cell viability, the results of Annexin V/PI staining and the analysis of the upstream and downstream mitochondrial apoptosis-associated proteins (Bcl-2,Bcl-xL, Bax, Bad, caspase-3
A
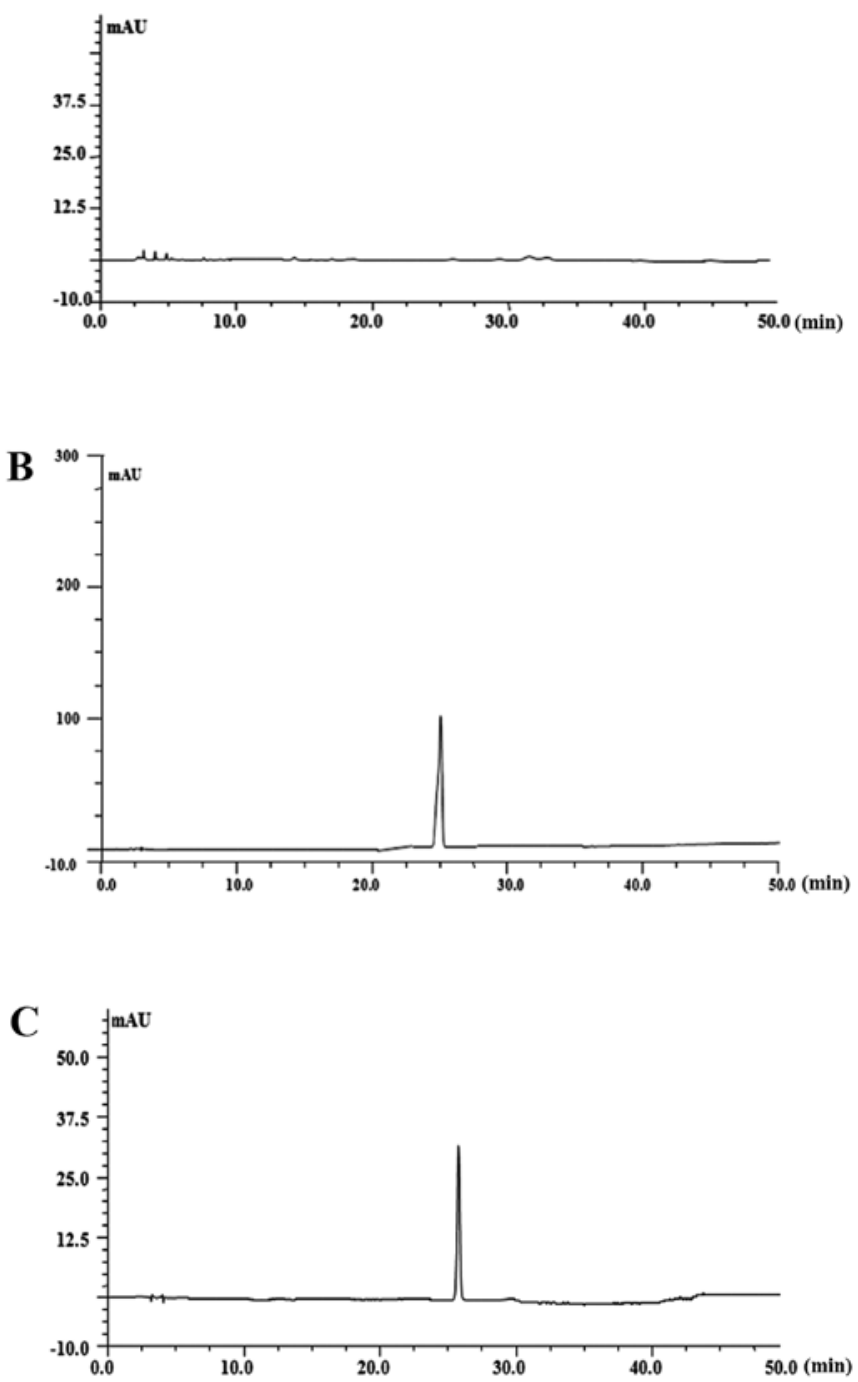

Figure 8. Determination of incorporation into $\mathrm{PC} 12$ cell of paeoniflorin (PF). PC12 cells were treated with $\mathrm{PF}(100 \mu \mathrm{M})$ in 6-holes culture plate. Following incubation for $24 \mathrm{~h}, 100 \mu \mathrm{l}$ intracellular extracts were aliquoted, and $20 \mu \mathrm{l}$ of each sample was subjected to HPLC analysis. (A) HPLC chromatograms were shown by blank culture medium, (B) PF standard and (C) intracellular PF. 
and -9), indicated that PF inhibited the apoptosis of PC12 cells induced by glutamate, which was consistent with the study of Sun et al (50). Their study proved that PF was able to protect PC12 cells from glutamate-induced cytotoxicity and apoptosis by investigating cell apoptosis, as well as mitochondrial membrane potential (MMP) by flow cytometric analysis and the expression profiles of Bcl-2 and Bax by western blot analysis. In this study, we demonstrated these effects by analyzing the protein expression profiles of Bcl-2, Bcl-xL, Bax, Bad, cleaved PARP, caspase-3 and caspase-9, as well as the mRNA expression of Bcl-2 and Bax. It is known that PF is a water-soluble compound, and not liposoluble compounds or materials are not easy to penetrate cell membranes (51). Thus, we investigated whether it can pass through the cytomembrane when PC12 cells were incubated with $\mathrm{PF}$ in vitro. The intracellular concentrations of $\mathrm{PF}$ in $\mathrm{PC} 12$ cells were determined by HPLC analysis. The results illustrated that PF had difficulty passing through cytomembrane, even after $24 \mathrm{~h}$ of incubation as only small amounts had passed through. This suggested that the protective effect of PF on glutamate-induced PC12 cell cytotoxicity was mainly provided with a small quantity of PF incorporating into the PC12 cells. Therefore, it was legitimately concluded that the elevation in the penetrability of PF could obviously produce a stronger protective effect than our present results in glutamate-exposed PC12 cells. Although PF has been proven to exert potent neuroprotective effects, and in this study we used PF to testify the intercellular peak, and we found that PF was detected in cells, we presumed that PF may be the active substance. PF may be metabolized in PC12 cells and perhaps its metabolite is also the active substance. This requires further investigation in future studies.

In conclusion, the results of this study indicated that $\mathrm{PF}$ is able to protect PC12 cells from glutamate-induced cytotoxicity and apoptosis by upregulating Bcl-2, Bcl-xL, downregulating Bax, Bad, cleaved PARP and ultimately inhibiting caspase-3 and caspase- 9 activity. Therefore, PF may be a potential neuroprotective compound which may be used to protect against neuronal injury induced by glutamate. However, further studies are required in order to further elucidate the underlying molecular mechanisms.

\section{Acknowledgements}

This study was carried out at the State Key Laboratory of Chinese Pharmacies of Fujian Provincial Department of Science and Technology, the Collaborative Innovation Center for Rehabilitation Technology, and the TCM Rehabilitation Research Center of SATCM. This study was supported by grants from the Project of Fujian Province Colleges and Universities in the New Century Excellent Talents, the National Natural Science Foundation of China (nos. 81503204 and 81674046), the 2015 Strategic Emerging Industries Project of Fujian Province (no. 2015Y0060).

\section{References}

1. Simerabet M, Robin E, Aristi I, Adamczyk S, Tavernier B, Vallet B, Bordet R and Lebuffe G: Preconditioning by an in situ administration of hydrogen peroxide: involvement of reactive oxygen species and mitochondrial ATP-dependent potassium channel in a cerebral ischemia-reperfusion model. Brain Res 1240: 177-184, 2008.
2. Donnan GA, Fisher M, Macleod M and Davis SM: Stroke. Lancet 371: 1612-1623, 2008.

3. Roger VL, Go AS, Lloyd-Jones DM, Adams RJ, Berry JD, Brown TM, Carnethon MR, Dai S, de Simone G, Ford ES, et al; American Heart Association Statistics Committee and Stroke Statistics Subcommittee: Heart disease and stroke statistics - 2011 update: a report from the American Heart Association. Circulation 123: e18-e209, 2011.

4. Peplow PV: Neuroimmunomodulatory effects of transcranial laser therapy combined with intravenous tPA administration for acute cerebral ischemic injury. Neural Regen Res 10: 1186-1190, 2015.

5. Zhang F, Yin W and Chen J: Apoptosis in cerebral ischemia: executional and regulatory signaling mechanisms. Neurol Res 26: 835-845, 2004.

6. Reyhane $\mathrm{H}$ and Homa $\mathrm{M}$ : A comprehensive review on anticancer mechanisms of the main carotenoid of saffron, crocin. J Pharm Pharmacol: Jul 3, 2017 (Epub ahead of print).

7. Liu Y, Peterson DA, Kimura H and Schubert D: Mechanism of cellular 3-(4,5-dimethylthiazol-2-yl)-2,5-diphenyltetrazolium bromide (MTT) reduction. J Neurochem 69: 581-593, 1997.

8. Atif F, Yousuf S and Agrawal SK: S-Allyl L-cysteine diminishes cerebral ischemia-induced mitochondrial dysfunctions in hippocampus. Brain Res 1265: 128-137, 2009.

9. Lu B: Mitochondrial dynamics and neurodegeneration. Curr Neurol Neurosci Rep 9: 212-219, 2009.

10. Wang Z, Lu W, Li Y and Tang B: Alpinetin promotes Bax translocation, induces apoptosis through the mitochondrial pathway and arrests human gastric cancer cells at the G2/M phase. Mol Med Rep 7: 915-920, 2013.

11. Adams JM and Cory S: Apoptosomes: engines for caspase activation. Curr Opin Cell Biol 14: 715-720, 2002.

12. Slee EA, Adrain C and Martin SJ: Executioner caspase-3, -6, and -7 perform distinct, non-redundant roles during the demolition phase of apoptosis. J Biol Chem 276: 7320-7326, 2001.

13. Burlacu A: Regulation of apoptosis by Bcl-2 family proteins. J Cell Mol Med 7: 249-257, 2003.

14. Szabò I, Soddemann M, Leanza L, Zoratti M and Gulbins E: Single-point mutations of a lysine residue change function of Bax and Bcl-xL expressed in Bax- and Bak-less mouse embryonic fibroblasts: novel insights into the molecular mechanisms of Bax-induced apoptosis. Cell Death Differ 18: 427-438, 2011.

15. Clem RJ, Cheng EH, Karp CL, Kirsch DG, Ueno K, Takahashi A, Kastan MB, Griffin DE, Earnshaw WC, Veliuona MA, et al: Modulation of cell death by Bcl-xL through caspase interaction. Proc Natl Acad Sci USA 95: 554-559, 1998.

16. Lin MY and Sheng ZH. Regulation of mitochondrial transport in neurons. Exp Cell Res 334: 35-44, 2015.

17. Chen YF, Wu KJ and Wood WG: Paeonia lactiflora extract attenuating cerebral ischemia and arterial intimal hyperplasia is mediated by paeoniflorin via modulation of VSMC migration and Ras/MEK/ERK signaling pathway. Evid Based Complement Alternat Med 2013: 482428, 2013.

18. Xiao L, Wang YZ, Liu J, Luo XT, Ye Y and Zhu XZ: Effects of paeoniflorin on the cerebral infarction, behavioral and cognitive impairments at the chronic stage of transient middle cerebral artery occlusion in rats. Life Sci 78: 413-420, 2005.

19. Tang NY, Liu CH, Hsieh CT and Hsieh CL: The anti-inflammatory effect of paeoniflorin on cerebral infarction induced by ischemia-reperfusion injury in Sprague-Dawley rats. Am J Chin Med 38: 51-64, 2010.

20. Guo RB, Wang GF, Zhao AP, Gu J, Sun XL and Hu G: Paeoniflorin protects against ischemia-induced brain damages in rats via inhibiting MAPKs/NF- $\mathrm{BB}$-mediated inflammatory responses. PLoS One 7: e49701, 2012.

21. Liu DZ, Xie KQ, Ji XQ, Ye Y, Jiang CL and Zhu XZ: Neuroprotective effect of paeoniflorin on cerebral ischemic rat by activating adenosine A1 receptor in a manner different from its classical agonists. Br J Pharmacol 146: 604-611, 2005.

22. Zhang Y, Li H, Huang M, Huang M, Chu K, Xu W, Zhang S, Que J and Chen L: Paeoniflorin, a monoterpene glycoside, protects the brain from cerebral ischemic injury via inhibition of apoptosis. Am J Chin Med 43: 543-557, 2015.

23. Wu YM, Jin R, Yang L, Zhang J, Yang Q, Guo YY, Li XB, Liu SB, Luo XX and Zhao MG: Phosphatidylinositol 3 kinase/protein kinase $\mathrm{B}$ is responsible for the protection of paeoniflorin upon $\mathrm{H}_{2} \mathrm{O}_{2}$-induced neural progenitor cell injury. Neuroscience 240: 54-62, 2013. 
24. Cao BY, Yang YP, Luo WF, Mao CJ, Han R, Sun X, Cheng J and Liu CF: Paeoniflorin, a potent natural compound, protects PC12 cells from $\mathrm{MPP}^{+}$and acidic damage via autophagic pathway. J Ethnopharmacol 131: 122-129, 2010.

25. Mao QQ, Zhong XM, Feng CR, Pan AJ, Li ZY and Huang Z: Protective effects of paeoniflorin against glutamate-induced neurotoxicity in $\mathrm{PC} 12$ cells via antioxidant mechanisms and $\mathrm{Ca}(2+)$ antagonism. Cell Mol Neurobiol 30: 1059-1066, 2010

26. Wang K, Zhu L, Zhu X, Zhang K, Huang B, Zhang J, Zhang Y, Zhu L, Zhou B and Zhou F: Protective effect of paeoniflorin on $\mathrm{A} \beta_{25-35}$-induced SH-SY5Y cell injury by preventing mitochondrial dysfunction. Cell Mol Neurobiol 34: 227-234, 2014.

27. Nam KN, Yae CG, Hong JW, Cho DH, Lee JH and Lee EH: Paeoniflorin, a monoterpene glycoside, attenuates lipopolysaccharide-induced neuronal injury and brain microglial inflammatory response. Biotechnol Lett 35: 1183-1189, 2013.

28. Li H, Ye M, Zhang Y, Huang M, Xu W, Chu K, Chen L and Que J: Blood-brain barrier permeability of Gualou Guizhi granules and neuroprotective effects in ischemia/reperfusion injury. Mol Med Rep 12: 1272-1278, 2015.

29. Que J, Ye M, Zhang Y, Xu W, Li H, Xu W and Chu K: Bryonolic acid, a triterpenoid, protect against $N$-methyl-d-aspartate-induced neurotoxicity in PC12 cells. Molecules 21: 418, 2016.

30. World Health Statistics 2011. World Health Organization, Geneva, Switzerland, p170, 2011.

31. Coyle JT and Puttfarcken P: Oxidative stress, glutamate, and neurodegenerative disorders. Science 262: 689-695, 1993.

32. Dirnagl U, Iadecola C and Moskowitz MA: Pathobiology of ischaemic stroke: an integrated view. Trends Neurosci 22: 391-397, 1999.

33. Takagi N, Besshoh S, Marunouchi T, Takeo S and Tanonaka K Effects of metabotropic glutamate mGlu5 receptor antagonist on tyrosine phosphorylation of NMDA receptor subunits and cell death in the hippocampus after brain ischemia in rats. Neurosc Lett 530: 91-96, 2012.

34. Hudspith MJ: Glutamate: a role in normal brain function, anaesthesia, analgesia and CNS injury. Br J Anaesth 78: 731-747, 1997

35. Cao LL, Du GH and Wang MW: The effect of salidroside on cell damage induced by glutamate and intracellular free calcium in PC12 cells. J Asian Nat Prod Res 8: 159-165, 2006.

36. Yu L, Wang N, Zhang Y, Wang Y, Li J, Wu Q and Liu Y: Neuroprotective effect of muscone on glutamate-induced apoptosis in PC12 cells via antioxidant and $\mathrm{Ca}(2+)$ antagonism. Neurochem Int 70: 10-21, 2014.

37. Kawakami Z, Kanno H, Ikarashi Y and Kase Y: Yokukansan, a kampo medicine, protects against glutamate cytotoxicity due to oxidative stress in PC12 cells. J Ethnopharmacol 134 74-81, 2011.
38. Ma S, Liu H, Jiao H, Wang L, Chen L, Liang J, Zhao Mand Zhang X: Neuroprotective effect of ginkgolide K on glutamate-induced cytotoxicity in PC12 cells via inhibition of ROS generation and $\mathrm{Ca}(2+)$ influx. Neurotoxicology 33: 59-69, 2012.

39. Wang $X$ and Zhu G: Study on protective effect of salvianolic acid B on glutamate-induced excitotoxicity in pheochromocytoma PC12 cells. Zhongguo Zhong Yao Za Zhi 37: 353-357, 2012 (In Chinese).

40. Song MX, Yang JC and Wang WP: A study of PC12 cell damage induced by glutamate. J Univer Sci Techno of Suzhou 23 62-65, 2006.

41. Broughton BR, Reutens DC and Sobey CG: Apoptotic mechanisms after cerebral ischemia. Stroke 40: e331-e339, 2009.

42. Ouyang YB and Giffard RG: MicroRNAs affect BCL-2 family proteins in the setting of cerebral ischemia. Neurochem Int 77 2-8, 2014.

43. Adams JM and Cory S: The Bcl-2 protein family: arbiters of cell survival. Science 281: 1322-1326, 1998.

44. Oltvai ZN, Milliman CL and Korsmeyer SJ: Bcl-2 heterodimerizes in vivo with a conserved homolog, Bax, that accelerates programmed cell death. Cell 74: 609-619, 1993.

45. Autret A and Martin SJ: Bcl-2 family proteins and mitochondrial fission/fusion dynamics. Cell Mol Life Sci 67: 1599-1606, 2010.

46. Martinou JC and Youle RJ: Mitochondria in apoptosis: Bcl-2 family members and mitochondrial dynamics. Dev Cell 21: 92-101, 2011

47. Liu X, Xu K, Yan M, Wang Y and Zheng X: Protective effects of galantamine against A $\beta$-induced PC12 cell apoptosis by preventing mitochondrial dysfunction and endoplasmic reticulum stress. Neurochem Int 57: 588-599, 2010.

48. Chornyy S, Parkhomenko J and Chorna N: Thiamine deficiency caused by thiamine antagonists triggers upregulation of apoptosis inducing factor gene expression and leads to caspase 3-mediated apoptosis in neuronally differentiated rat PC-12 cells. Acta Biochim Pol 54: 315-322, 2007.

49. Zhang Y, Goodyer C and LeBlanc A: Selective and protracted apoptosis in human primary neurons microinjected with active caspase-3, -6, -7, and -8. J Neurosci 20: 8384-8389, 2000.

50. Sun R, Wang K, Wu D, Li X and Ou Y: Protective effect of paeoniflorin against glutamate-induced neurotoxicity in $\mathrm{PC} 12$ cells via Bcl-2/Bax signal pathway. Folia Neuropathol 50: 270-276, 2012.

51. Tanaka T, Kataoka M, Tsuboi N and Kouno I: New monoterpene glycoside esters and phenolic constituents of Paeoniae radix, and increase of water solubility of proanthocyanidins in the presence of paeoniflorin. Chem Pharm Bull (Tokyo) 48: 201-207, 2000. 